\title{
“KAIL SEJENGKAL JANGANLAH MENDUGA DALAM LAUTAN": MENGAPA PSIKOLOGI PERLU LEBIH DARIPADA STUDI EMPIRIS
}

\author{
Karel Karsten Himawan \\ Fakultas Psikologi, Universitas Pelita Harapan, Jl. M. H. Thamrin Boulevard 1100, Tangerang, Banten 15811, Indonesia
}

Korespondensi: karel.karsten@uph.edu

\section{"AN INCH OF A HOOK CANNOT PREDICT THE DEPTH OF A SEA": WHY PSYCHOLOGY NEEDS MORE THAN EMPIRICAL STUDIES}

\begin{abstract}
Most studies in psychology are built on the evidence-based paradigm, which heavily relies on the objectivity (positivism) as well as integrity and competency of the researchers (constructivism) to interpret the reality. Such a paradigm is often implemented in a reductionistic manner, where all studies in psychology have to employ analysis of primary data. This reflects what currently occurs in Indonesia where most scientific outlets in psychology seem to put much interest on manuscripts that report quantitative and/or qualitative study. In this editorial note, I introduce various possible alternative methods to justify the truth and utility values apart from empirical analysis. This note also informs various practical strategies of the journal to accommodate publication of peer-reviewed, nonempirical work for rapid and accurate dissemination of new knowledge in the field of Indonesian indigenous psychology.
\end{abstract}

Manuscript type: Editorial Note

\section{Article history:}

Received 21 October 2020

Accepted 21 October 2020

Available online 23 October 2020

\section{Keywords:}

empirical study

empirism

evidence-based

literature review

scientific publication in Indonesia

\begin{abstract}
Abstrak
Mayoritas studi di bidang psikologi menekankan pada paradigma berbasis pada bukti yang mengandalkan observasi objektif (positivisme) maupun integritas dan kompetensi peneliti (konstruktivisme) dalam menginterpretasikan sebuah realita. Paradigma ini seringkali diimplementasikan secara reduksionistik, di mana studi ilmiah di bidang psikologi hanya dapat dilakukan melalui metode empiris yang mengandalkan data primer. Ini adalah realita yang terjadi, terutama di Indonesia, di mana kebanyakan publikasi ilmiah di bidang psikologi mengisyaratkan studi empiris dengan metode kuantitatif dan/atau kualitatif. Dalam catatan ini, saya memperkenalkan berbagai metode alternatif selain studi yang mengandalkan data primer untuk menjustifikasi nilai kebenaran dan kegunaan dari suatu argumen. Berkenaan dengan hal itu, catatan ini juga hendak menginformasikan langkah strategis Jurnal Psikologi Ulayat untuk mewadahi bentuk publikasi dengan telaah sejawat selain studi empiris demi mewujudkan diseminasi yang cepat dan akurat mengenai perkembangan pengetahuan di bidang psikologi ulayat di Indonesia.
\end{abstract}

Kata Kunci: berbasis bukti, empiris, kajian literatur, publikasi ilmiah di Indonesia, studi empiris

Kail sejengkal janganlah menduga dalam lautan. Peribahasa populer ini memberikan pesan moral yang penting untuk berhati-hati dalam menerka sesuatu karena ilmu pengetahuan yang dimilikinya mungkin masih terbatas. Saya pikir peribahasa ini cukup akurat merepresentasikan arus perkembangan publikasi ilmiah di bidang psikologi di Indonesia. Atas nama pendekatan ilmiah, banyak ilmuwan yang terkungkung dalam pemahaman bahwa studi empiris dengan mengandalkan data primer adalah cara yang paling valid untuk "menerka" dalam dan luasnya fenomena psikologis yang diteliti, sehingga terjebak pada generalisasi berlebihan. Hal ini tercermin dari mayoritas jurnal ilmiah psikologi di Indonesia saat ini yang menekankan pada publikasi studi empiris saja.

Keraguan atas validitas pendekatan empirisme dalam bidang psikologi sudah banyak diutarakan (cth. Smedslund, 2016). Namun, bahwa pendekatan empirisme dalam bidang psikologi masih diperdebatkan bukan menjadi fokus catatan ini. Catatan ini hendak berfokus pada memperkenalkan "kail" alternatif dalam upaya menerka sebuah dunia kebenaran di bidang 
psikologi dengan berbagai derajat akurasinya. Kritik terhadap studi empirisme di antaranya ialah cenderung mengandalkan pada rata-rata populasi, yang seolah-olah menurunkan nilai keabsahan individu yang berada pada posisi ekstrem kiri atau kanan grafik distribusi normal. Kail alternatif yang ingin diperkenalkan ialah temuan berdasarkan studi kajian literatur, studi kasus atau studi bersampel kecil, dan temuan unik berdasarkan pengalaman praktis pakar di bidangnya.

Studi literatur kurang diminati oleh peneliti di Indonesia bisa jadi disebabkan oleh terbatasnya jurnal yang mempublikasikan hasil kajian literatur. Padahal kajian literatur menempati posisi teratas pada hierarki kebenaran, lebih tinggi daripada klaim yang dibuat oleh studi empiris (El Hafiz \& Himawan, 2020). Ini disebabkan karena studi literatur mengintegrasikan temuan dari berbagai studi empiris yang telah dilakukan pada topik yang sama. Di sisi lain, studi kasus yang seringkali mengandalkan satu subjek saja juga tidak boleh diremehkan nilai kebenarannya. Bao dkk. (2017) mengilustrasikan pentingnya studi kasus dalam memberikan informasi yang unik dan bermanfaat untuk memahami individu yang berada di area "di luar rata-rata", sehingga psikologi bukan hanya didedikasikan bagi mereka yang ada di kelompok rata-rata saja.

Dengan semangat inilah, Jurnal Psikologi Ulayat memperkenalkan jenis publikasi baru selain studi empiris (original research), yaitu kajian literatur (literature review), studi kasus (brief report), dan argumen opini kritis (commentary paper). Edisi ini menjadi edisi perdana di mana Jurnal Psikologi Ulayat mempublikasikan naskah studi kasus tentang pengintegrasian dua pendekatan psikoterapi dalam menangani individu dengan diagnosis yang spesifik (gangguan somatis dengan kecenderungan kepribadian schizoid-avoidant) (Devany \& Poerwandari, 2020). Di terbitan berikutnya, siap terbit artikel argumen kritis mengenai tantangan melakukan kajian literatur psikologi di Indonesia (El Hafiz \& Himawan, 2020).

Dengan meningkatnya kualitas dan lingkup pembaca Jurnal Psikologi Ulayat yang diindikasikan dari diperolehnya peringkat SINTA 2 dan indeksasi jurnal di berbagai basis data internasional, diharapkan dapat mengakomodasi kail alternatif dalam mengungkap lebih dalam pengetahuan tentang berbagai fenomena psikologi di Indonesia, yang sampai saat ini tampaknya masih menyingkap wilayah permukaannya saja.

\section{REFERENSI}

Bao, Y., Pöppel, E., \& Zaytseva, Y. (2017). Single case studies as a prime example for exploratory research. PsyCH Journal, 6(2), 107-109. doi:10.1002/pchj.176

Devany, K., \& Poerwandari, E. K. (2020). Integrating cognitive-behavioral therapy and gratitude therapy for treating somatic symptom disorder with schizoid-avoidant personality features: A case report. Jurnal Psikologi Ulayat: Indonesian Journal of Indigenous Psychology, 7(2), 113-121. doi:10.24854/jpu127

El Hafiz, S., \& Himawan, K. K. (2020). Tantangan melakukan kajian literatur psikologi di Indonesia: Masalah mendasar dan solusinya. Jurnal Psikologi Ulayat: Indonesian Journal of Indigenous Psychology. Advance online publication. doi:10.24854/jpu125

Smedslund, J. (2016). Why psychology cannot be an empirical science. Integrative Psychological and Behavioral Science, 50(2), 185-195. doi:10.1007/s12124-015-9339-x 